\title{
Phase II study of everolimus with biomarker exploration in patients with advanced gastric cancer refractory to chemotherapy including fluoropyrimidine and platinum
}

\author{
DH Yoon ',3, M-H Ryu ',3, YS Park', ', HJ Lee', C Lee', B-Y Ryoo', J-L Lee', H-M Chang', TW Kim' and Y-K Kang ', I \\ 'Department of Oncology, Asan Medical Center, University of Ulsan College of Medicine, Seoul, Korea; ${ }^{2}$ Department of Pathology, Asan Medical Center, \\ University of Ulsan College of Medicine, Seoul, Korea
}

BACKGROUND: To evaluate the activity and safety of everolimus and identify potential biomarkers for efficacy of everolimus in patients with advanced gastric cancer (AGC), who failed both fluoropyrimidine and platinum.

METHODS: Fifty-four patients received everolimus $\left(10 \mathrm{mg} \mathrm{day}^{-1}\right)$. The primary objective was to determine the 4-month progressionfree survival (PFS) rate, assumed to be $30 \%$. We additionally investigated the potential biomarkers for everolimus as an exploratory endpoint in those who underwent tumour biopsies.

RESULTS: Two patients (3.7\%) achieved partial response and the disease control rate (DCR) was 38.9\%. At a median follow-up duration of 8.7 months, the 4-month PFS rate was 18.4\%, not fulfilling the primary hypothesis, with a median PFS of 1.7 months and a median overall survival of 8.3 months. The high expression of pS6 ${ }^{\text {Ser2 } 240 / 4}$ at baseline was significantly associated with higher DCR $(P=0.043)$ and prolonged PFS $(P=0.00$ I $)$. Grade I/2 asthenia $(96.3 \%)$ recorded as the leading toxicity and hyperglycaemia $(20.4 \%)$ was the most common non-hematological grade 3/4 toxicity. Three patients experienced grade 3/4 pneumonitis. Notably, two experienced treatment-related deaths.

CONCLUSION: Everolimus is active against a limited number of patients with AGC. pS6 $6^{\mathrm{Ser} 240 / 4}$ may be a potential predictive biomarker for everolimus, which requires validation. Careful monitoring is necessary despite generally favourable toxicity profile.

British Journal of Cancer (2012) I 06, 1039-1044. doi:I0.1038/bjc.2012.47 www.bjcancer.com

Published online 16 February 2012

(C) 2012 Cancer Research UK

Keywords: everolimus; advanced gastric cancer; biomarker

Despite a worldwide decrease in incidence, gastric cancer remains the fourth most common cancer type and the second most common cause of cancer-related mortality worldwide (Parkin et al, 2005; Kamangar et al, 2006). Chemotherapy is the standard of care for advanced or recurrent gastric cancer, but median overall survival (OS) is $<1$ year, with response rates of around $20-40 \%$ (Kang et al, 2010). Furthermore, current salvage chemotherapy after failure of first-line fluoropyrimidine-based chemotherapy has produced few and short-lived tumour responses, is effective in very limited patient populations, and causes severe toxicity.

The phosphoinositide-3-kinase (PI3K)/mammalian target of rapamycin (mTOR) pathway is frequently dysregulated in many human cancers, and inhibition of the mTOR pathway as a new therapeutic target is an active area of research (Frattini et al, 2005; Velho et al, 2005). mTOR, a key protein kinase present in all cells, regulates cell growth, proliferation and survival (Frattini et al, 2005; Velho et al, 2005; Ciuffreda et al, 2010). mTOR acts by

*Correspondence: Dr Y-K Kang; E-mail: ykkang@amc.seoul.kr Presented in part at the 35th European Society of Medical Oncology (ESMO) Congress held in Milan, Italy, 2010 and the 20I I Gastrointestinal Cancers Symposium held in San Francisco, CA, USA.

${ }^{3}$ These authors contributed equally to this work and should be considered as joint first authors.

Received 5 September 2011; revised 18 January 2012; accepted 20 January 2012; published online 16 February 2012 directly activating ribosomal protein S6 kinase 1 (S6K1) and inhibiting a translational repressor, 4E-binding protein 1 (4EBP1) (Iwenofu et al, 2008). S6K1 phosphorylates the S6 protein of the 40s ribosomal subunit at several sites, including Ser 235/236 and Ser $240 / 244$, leading to initiation of protein synthesis (Dufner et al, 1999; Iwenofu et al, 2008).

Everolimus is a novel macrolide derivative of rapamycin that inhibits the ability of mTOR to phosphorylate S6K1 and 4EBP1, thereby causing G0/G1 arrest and inhibiting cell-cycle progression in cancer cells (Bjornsti and Houghton, 2004). In the first phase II study on patients with advanced gastric cancer (AGC), everolimus was well tolerated with a promising disease control rate (DCR) (Doi et al, 2010). Based on these results, a large-scale phase III trial investigating the effects of everolimus on AGC is currently ongoing. However, the molecular determinants that predict the responsiveness of tumour cells to everolimus remain to be established. In the current phase II trial of everolimus involving heavily pretreated AGC patients, we have conducted immunohistochemical (IHC) analysis of molecules related to the mTOR signalling pathway from baseline and/or on-therapy sequential biopsies.

\section{PATIENTS AND METHODS}

\section{Patients}

This is a prospective, open-label, single arm phase II study. Patients with advanced, unresectable and histologically confirmed 
adenocarcinomas of the stomach were eligible if they met the following inclusion criteria: (1) age 18-75 years, (2) Eastern Cooperative Oncology Group performance status $0-2$, (3) prior failure of first-line chemotherapy, including fluoropyrimidine (5-FU) or related drugs (capecitabine, doxifluridine, S1 or tegafur-uracil (UFT)) and platinum (cisplatin or oxaliplatin) chemotherapy, (4) measurable lesions based on the Response Evaluation Criteria in Solid Tumours (RECIST), (5) no previous radiotherapy to $>25 \%$ of bone marrow, (6) estimated life expectancy of over 3 months, (7) adequate bone marrow, renal and hepatic functions and (8) written informed consent. Patients were excluded in cases of the brain metastases, significant gastrointestinal bleeding or obstruction and serious comorbid conditions or if they lacked the ability to comply with the protocol requirements. This study was approved by the institutional review board of the Asan Medical Center and registered in clinicaltrials. gov. (NCT00729482).

\section{Treatment and assessment}

Everolimus was administered at a dose of $10 \mathrm{mg}$ (two $5 \mathrm{mg}$ tablets) orally every day until progression of disease, unacceptable toxicity, or study discontinuation for any other reason. Each cycle comprised 28 days of treatment. Treatment was reduced to $5 \mathrm{mg} \mathrm{day}^{-1}$ and subsequently to $5 \mathrm{mg}$ every other day for specific toxicities. Tumour response was evaluated every two treatment cycles according to RECIST version 1.0. Toxicities were evaluated at day 1 of each cycle according to the National Cancer Institute Common Terminology Criteria for Adverse Events (NCI-CTCAE) scale, version 3.0.

\section{Statistics}

The primary end-point was progression-free survival (PFS). Secondary end-points included response rate, OS and toxicity profiles. Fleming's single-stage one sample design required 48 assessable subjects to determine whether the proportion of patients surviving without progression at 4 months (16 weeks), $P$, was $\leqslant 0.15$ or $\geqslant 0.30$, with $\alpha$ of 0.05 and $\beta$ of 0.2 . Assuming a dropout rate of $10 \%$, total accrual of 54 patients was required. Fisher's exact test was used to examine the effects of biomarkers on DCR and the Wilcoxon's signed-rank test was used to analyse the changes from baseline in various biomarkers after treatment with everolimus. Kaplan-Meier estimates were applied to summarise the distribution of time-to-event variables, such as PFS and OS, and the Cox proportional hazards regression model to identify potential prognostic factors or biomarkers for predicting prolonged PFS or OS. The SPSS programme for Windows (SPSS Inc., Chicago, IL, USA) was employed for statistical analysis.

\section{Biopsy samples}

As an exploratory end-point, the influence of biomarkers on efficacy outcome variables was investigated. The objective of this translational research was to identify the profiles of patients that would benefit from everolimus and determine whether the drug effectively inhibits the mTOR pathway in gastric cancer tissue. Fresh tumour biopsies were obtained at screening (before everolimus treatment, $n=23$ ) and after two cycles of treatment $(n=19)$ for consensual patients who did not receive gastrectomy and thus had cancer lesions in the stomach.

\section{Immunohistochemical staining}

Immunohistochemical staining was performed on formalin-fixed, paraffin-embedded tissue sections using the automatic IHC staining device (Benchmark XT, Ventana Medical Systems, Tucson, AZ, USA). Briefly, $4 \mu \mathrm{m}$ thick whole tissue sections were transferred onto poly-L-lysine-coated adhesive slides and dried at $74^{\circ} \mathrm{C}$ for
Table I Baseline patient characteristics

\begin{tabular}{|c|c|}
\hline Characteristic & $\mathbf{N}=\mathbf{5 4}(\%)$ \\
\hline Male $(n, \%)$ & $45(83.3)$ \\
\hline Age, years, median (range) & $57.5(27-72)$ \\
\hline \multicolumn{2}{|l|}{ ECOG performance } \\
\hline $0-1$ & $54(100)$ \\
\hline \multicolumn{2}{|l|}{ Tumour differentiation } \\
\hline Well differentiated & $2(3.7)$ \\
\hline Moderately differentiated & $27(50.0)$ \\
\hline Poorly differentiated & $20(37.0)$ \\
\hline Signet ring cell cancer & $5(9.3)$ \\
\hline \multicolumn{2}{|l|}{ Site of metastasis } \\
\hline Liver & $27(50.0)$ \\
\hline Peritoneum & $12(22.2)$ \\
\hline Abdominal lymph node & $40(74.1)$ \\
\hline Ovary & $3(5.6)$ \\
\hline Bone & $1(1.9)$ \\
\hline Lung & $2(3.7)$ \\
\hline Left supraclavicular lymph node & $4(7.4)$ \\
\hline Others $^{\mathrm{a}}$ & $2(3.7)$ \\
\hline Prior gastrectomy & $23(42.6)$ \\
\hline Adjuvant chemotherapy & $15(27.7)$ \\
\hline \multicolumn{2}{|l|}{ Prior chemotherapy } \\
\hline Fluoropyrimidine & $52(100)$ \\
\hline Platinum & $52(100)$ \\
\hline Docetaxel & $19(35.2)$ \\
\hline Irinotecan & $2(3.7)$ \\
\hline
\end{tabular}

Abbreviation: $\mathrm{ECOG}=$ Eastern Cooperative Oncology Group. ${ }^{\mathrm{a} O t h e r}$ site: adrenal gland $(n=1)$, psoas muscle $(n=1)$.

$30 \mathrm{~min}$. After standard heat epitope retrieval for $1 \mathrm{~h}$ in ethylene diamine tetraacetic acid, pH.8.0, in the autostainer, samples were incubated with antibodies against phosphorylated mTOR (pmTOR, 1:200 dilution, clone 49F9, rabbit monoclonal, Cell Signaling Technology, Danvers, MA, USA), pS6K1 (1:100 dilution, clone E175, rabbit monoclonal, Epitomics, Burlingame, CA, USA), pS6 at Ser 235/6 (pS6 ${ }^{\text {Ser235/6 }}, 1: 150$ dilution, clone 91B2, rabbit monoclonal, Cell Signaling Technology), pS6 at Ser 240/4 (pS6 ${ }^{\text {Ser240/4, }}$ $1: 200$ dilution, rabbit polyclonal, Cell Signaling Technology) and p4EBP1 (1:400 dilution, clone 236B4, rabbit monoclonal, Cell Signaling Technology). Sections were subsequently incubated with the UltraView Universal DAB kit (Ventana Medical Systems). Slides were counterstained with Harris hematoxylin. Because of insufficient availability of histological sections, immunostaining for p4EBP1 could not be performed in one follow-up biopsy sample.

\section{Evaluation of IHC staining data}

Immunohistochemical results were scored based on the percentage of positive cells. The proportions of positive tumour cells were categorically scored as $0(0 \%), 1(<10 \%), 2(10 \%$ to $1 / 3), 3(1 / 3$ to $2 / 3)$ and $4(\geqslant 2 / 3)$. Aberrant expression of pmTOR, pS6K1, $\mathrm{pS}^{\text {Ser235/6 }}, \mathrm{pS6} 6^{\text {Ser240/4 }}$ and p4EBP1 was assessed from cytoplasmic staining, and tumour cells showing more than weak staining intensity were interpreted as positive. Negative controls were performed by omitting the primary antibodies.

\section{RESULTS}

\section{Patient characteristics}

From July 2008 to February 2010, 54 eligible patients were entered in the study. Patient characteristics are listed in Table 1. In 
addition to fluoropyrimidine and platinum (FP), 19 patients were refractory to docetaxel and two failed irinotecan, respectively. Twelve patients were diabetic.

\section{Drug administration}

A total of 180 cycles of everolimus were administered for a median of 2 (range, 1-20) cycles per patient. At the time of data cut-off, three patients were on everolimus and the others had discontinued treatment. Disease progression was the primary reason for treatment termination. Specifically, 44 patients discontinued treatment because of disease progression, five owing to toxicity and two of their own will.

\section{Efficacy}

Responses were not assessable in three patients. One patient refused treatment before response evaluation, another discontinued treatment early because of grade 4 thrombocytopenia and the other died of cardiopulmonary dysfunction before evaluation. Among the 51 assessable patients, two (3.7\%) achieved confirmed partial response (PR). One 27-year-old man with multiple liver metastases and abdominal lymph nodes, who had previously failed both S-1 and FOLFOX, attained PR after the eighth cycle and was still on everolimus treatment at the twentieth cycle, with a PR duration of 12.1 months. The other patient, 49-year-old woman with abdominal lymph node metastases, who previously underwent combination chemotherapy of S1 and cisplatin, attained PR after the second cycle and everolimus treatment was maintained for 12 cycles, with a PR duration of 10.0 months at the time of data cut-off. Another 19 patients $(35.2 \%)$ showed stable disease, resulting in a DCR of $38.9 \%$, whereas decreases in the sizes of target lesions from baseline were observed in 16 patients (29.6\%) (Figure 1A). The maximum size reduction rate $(64.3 \%)$ was observed in the patient achieving confirmed PR. At a median follow-up duration of 8.7 months in surviving patients (range, 3.0-19.4 months), the 4-month PFS rate was $18.4 \%$, with a median PFS of 1.7 months (95\% confidence interval (CI) 1.5-2.2 months) (Figure 1B). At the time of data cutoff, 32 patients had died ( 30 because of disease progression and two from treatment-related causes), resulting in median OS of 8.3 months (95\% CI, 4.5-12.1 months).

The PFS and OS values did not change with patient age $(<60$ years $v s \geqslant 60$ years), histological differentiation, tumour burden $(<6 \mathrm{~cm} v s \geqslant 6 \mathrm{~cm})$, prior gastrectomy and presence of metastasis in the liver or abdominal lymph node. Peritoneal carcinomatosis and number of metastatic sites $(1 v s \geqslant 2)$ were significantly associated with shorter PFS times in both univariate (hazard ratio (HR) $3.974,95 \%$ CI $1.54-10.23, P=0.010$; HR 2.319, 95\% CI $1.234-4.357, P=0.006)$ and multivariate analyses $(P=0.043$ and 0.017 , respectively) (Supplementary Table A1 and A2, online only).

\section{Biomarker analysis}

In total, 23 baseline biopsies and 19 sequential on-therapy biopsies were available for IHC analysis. Among the IHC biomarkers examined, $\mathrm{pS}^{\mathrm{Ser} 235 / 6}$ and $\mathrm{pS}^{\mathrm{Ser} 240 / 4}$ were the most frequently expressed $(96.4 \%$ for both), followed by p4EBP1, pmTOR and pS6K1. Treatment with everolimus resulted in significant inhibition in S6 phosphorylation at Ser 235/6 and Ser 240/4 $(P=0.0004$ and 0.0008 , respectively), whereas pS6K1 and p4EBP1 levels were not markedly reduced $(P=0.2817$ and 0.4326$)$ (Supplementary Figure A1, online only, and Figure 3 ). We explored the potential relationships between baseline or changes in the expression levels of markers and clinical outcomes, including DCR, PFS and OS. High expression of baseline $\mathrm{pS}^{\mathrm{Ser} 240 / 4}$ (IHC score $\geqslant 2$ ) or marked decrease (IHC score $\geqslant 2$ ) in $\mathrm{pS}^{\text {Ser235/6 }}$ expression were significantly associated with higher rates of disease control, achieving clinical response or stable disease $(P=0.043$ and 0.041 , respectively)
A
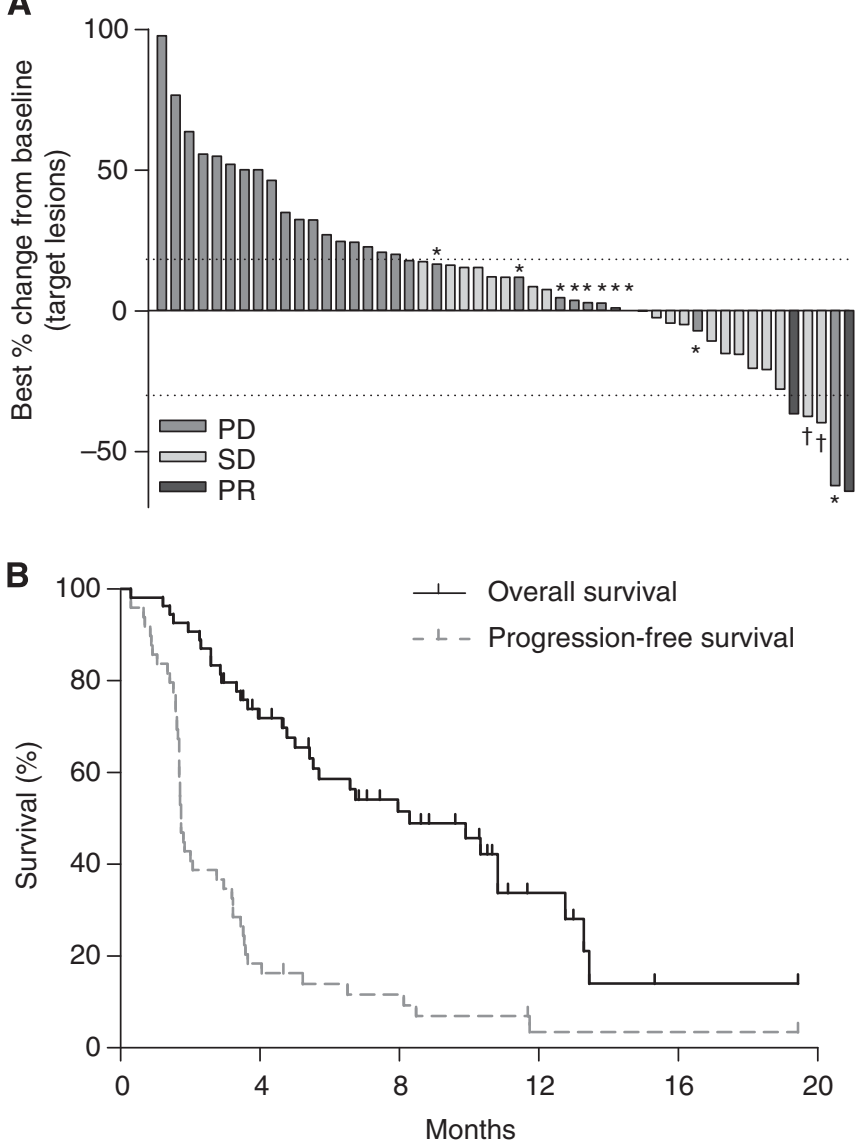

Figure I Greatest percentage change from baseline in sum of longest diameters $(\mathbf{A})$. Progression-free survival and $\mathrm{OS}$ times (B). *Progressive disease because of appearance of new metastatic lesions or unequivocal progression of non-target lesions. †nconfirmed PR. Abbreviations: $\mathrm{PD}=$ progressive disease; $\mathrm{SD}=$ stable disease.

(Supplementary Table A3, online only). In addition, the baseline levels of pmTOR, pS6 $6^{\text {Ser235/6 }}$ and $\mathrm{pS}^{\text {Ser240/4 }}$ were significantly correlated with PFS $(P=0.005,0.006$ and 0.001 , respectively) (Table 2, Figure 2). Additionally, relative decreases in $\mathrm{pS6} 6^{\mathrm{Ser} 235 / 6}$ expression by at least 2 IHC scores and $\mathrm{pS6}^{\mathrm{Ser} 240 / 4}$ by at least 1 IHC score were significant predictors of PFS $(P=0.005$ and 0.031 . respectively), whereas the relative increase in pmTOR was associated with prolonged PFS $(P=0.004)$. In multivariate analysis with other variables, including the presence of peritoneal carcinomatosis and number of metastatic lesions $(1 v s \geqslant 2)$, baseline expression of $\mathrm{pS}^{\text {Ser240/4 }}$ (IHC score $<2 v s \geqslant 2$ ) was still a significant predictor of PFS (HR 0.246, 95\% CI 0.078-0.777, $P=0.017)$, whereas baseline and/or changes in expression of pmTOR $(<2 v s \geqslant 2)$ and $\mathrm{pS}^{\operatorname{Ser} 235 / 6}(<3 v s \geqslant 3)$ showed marginal statistical significance $(P=0.076$ and 0.100$)$ (Supplementary Table A4-A6, online only). Representative biomarker expression levels before and after two cycles of treatment with everolimus from the 27-year-old man showing PR are presented in Figure 3. The second patient achieving PR did not underwent biopsy for biomarker study.

\section{Toxicity}

Treatment was delayed in 24 patients (44.4\%). The doses were reduced in five $(9.3 \%)$ patients because of adverse events, including recurrent grade 2 stomatitis in two patients, recurrent grade 2 thrombocytopenia in two patients and grade 3 thrombo- 
Table 2 IHC markers (at baseline biopsy) vs progression-free survival (PFS) and overall survival (OS)

\begin{tabular}{|c|c|c|c|c|c|}
\hline $\begin{array}{l}\text { Biomarkers } \\
\text { (before } \\
\text { treatment) }\end{array}$ & $N$ & $\begin{array}{l}\text { Median PFS } \\
(95 \% \mathrm{CI})\end{array}$ & $P$-value & $\begin{array}{l}\text { Median OS } \\
(95 \% \mathrm{Cl})\end{array}$ & $P$-value \\
\hline $\begin{array}{c}\text { PmTOR } \\
<2 \\
\geqslant 2\end{array}$ & $\begin{array}{l}15 \\
13\end{array}$ & $\begin{array}{l}1.645(1.421-1.869) \\
2.763(1.142-4.384)\end{array}$ & 0.005 & $\begin{array}{l}5.526(3.148-7.905) \\
6.743(1.638-11.849)\end{array}$ & 0.425 \\
\hline $\begin{array}{c}\text { pS6 kinase } \\
<4 \\
\geqslant 4\end{array}$ & $\begin{array}{l}16 \\
12\end{array}$ & $\begin{array}{l}1.678(1.484-1.87 I) \\
1.743(1.360-2.127)\end{array}$ & 0.150 & $\begin{array}{l}10.822 \text { (NR) } \\
5.526(3.094-7.958)\end{array}$ & 0.599 \\
\hline $\begin{array}{c}p S 6^{\text {Ser } 235 / 6} \\
\quad<3 \\
\geqslant 3\end{array}$ & $\begin{array}{l}14 \\
14\end{array}$ & $\begin{array}{l}1.612(1.491-1.732) \\
2.072(0.566-3.579)\end{array}$ & 0.006 & $\begin{array}{c}5.526(2.810-8.243) \\
10.822(4.332-17.313)\end{array}$ & 0.224 \\
\hline $\begin{array}{c}p S 6^{\text {Ser } 240 / 4} \\
<2 \\
\geqslant 2\end{array}$ & $\begin{array}{l}13 \\
15\end{array}$ & $\begin{array}{l}1.579(1.347-1.811) \\
2.763(1.174-4.352)\end{array}$ & 0.001 & $\begin{array}{c}4.638(2.215-7.061) \\
10.822(4.909-16.736)\end{array}$ & 0.073 \\
\hline $\begin{array}{c}\text { p4EBPI } \\
<2 \\
\geqslant 2\end{array}$ & $\begin{array}{r}9 \\
18\end{array}$ & $\begin{array}{l}1.743(1.647-1.840) \\
1.743(1.675-1.811)\end{array}$ & 0.354 & $\begin{array}{l}10.822(\mathrm{NR}) \\
5.000(2.137-7.863)\end{array}$ & 0.117 \\
\hline
\end{tabular}

Abbreviations: $\mathrm{NR}=$ not reached; $\mathrm{p} 4 \mathrm{EBPI}=$ phosphorylated $4 \mathrm{E}$ binding protein I; $\mathrm{pmTOR}=$ phosphorylated mammalian target of rapamycin.

cytopenia in one patient. In total, seven patients discontinued treatment because of adverse events or intolerance to everolimus. The mean relative dose intensity per patient was $95.3 \pm 10.0 \%$. The most common haematological toxicity was grade 1 or 2 anaemia. Although 15 patients (27.8\%) experienced grade 3 or 4 lymphopenia, no clinically significant viral/fungal infection was observed. In addition, no grade 3 or 4 leukopenia or febrile neutropenia was reported (Table 3 ). In terms of non-hematological grade 3 or 4 toxicities, hyperglycaemia was the most frequent (20.4\%), followed by elevation of the $\gamma$-glutamyl transpeptidase level (18.5\%), and electrolyte imbalance, including hyponatremia (16.7\%) and hypophosphatemia (16.7\%). Six among eleven patients experiencing grade 3 or 4 hyperglycaemia were diabetics on treatment for glycemic control. Three patients experienced grade 3 or 4 pulmonary toxicity. One patient was diagnosed as grade 3 pneumonitis after four cycles of everolimus, which improved following steroid treatment for 2 weeks. However, another patient suffered from diffuse alveolar haemorrhage and died of respiratory failure. In addition, one patient suddenly developed hypoxaemia and heart failure on the eighth day of the first cycle and died of cardiopulmonary dysfunction. The specific cause of death could not be identified, as an autopsy was not performed in this case. In total, two treatment-related deaths were recorded.

\section{DISCUSSION}

In this phase II study, everolimus monotherapy, administered at a dose of $10 \mathrm{mg} \mathrm{day}^{-1}$ in unselected patients, failed to achieve a predefined efficacy goal of 4-month PFS rate of $30 \%$ against heavily pretreated AGC, despite its mild toxicity. We have further identified potential biomarkers for predicting clinical outcomes following administration of everolimus, based on IHC analysis of baseline and sequential biopsies of primary cancer. Our results suggest that tumours that do not involve activation of the mTOR pathway may not benefit from everolimus treatment.

A DCR of $38.9 \%$ with median PFS of 1.7 months and median OS of 8.3 months appeared slightly inferior, compared with the DCR of $56.0 \%$, median PFS of 2.7 months and median OS of 10.1 months reported from the earlier Japanese phase II trial (Doi et al, 2010). These discrepancies may be attributed, at least in part, to
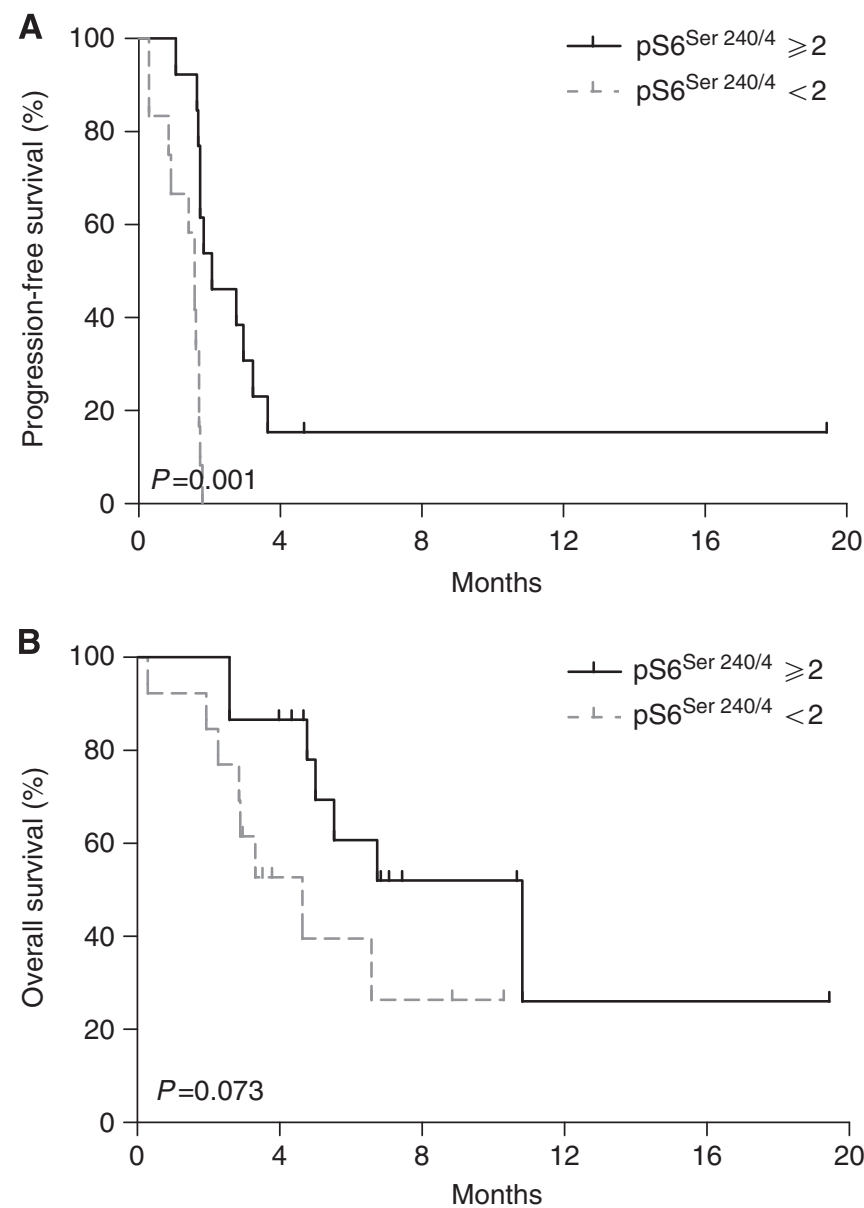

Figure 2 Progression-free survival $(\mathbf{A})$ and $O S(\mathbf{B})$ times based on baseline expression of pS6 $6^{\text {Ser240/4 }}$ (immunohistochemistry score $<2$ vs $\geqslant 2$ ).

different patient characteristics, as our trial included very heavily pretreated patients that failed both FP. In addition, $22.1 \%$ of patients had peritoneal carcinomatosis, which was a poor prognostic factor in multivariate analysis, compared with $8 \%$ of patients in the Japanese trial. Thus, our findings do not necessarily refute the results of the Japanese phase II trial. However, only 2 out of 107 patients from two phase II trials achieved objective response, suggesting that the efficacy of everolimus in the treatment of AGC is unsatisfactory, compared with conventional chemotherapy. A phase II study of docetaxel previously performed in our centre on patients with similar characteristics to those enrolled in the everolimus trial revealed overall response rate of $16.5 \%$, DCR of $57 \%$ and median TTP of 2.5 months (Lee et al, 2008), which appear superior to data from the present phase II trial. However, two patients treated with everolimus achieved longterm PR that lasted for at least 12.1 and 10.0 months, despite prior failure of S-1 and FOLFOX in one patient, and S1 plus cisplatin in the other. Considering the long-term benefits for these patients, identification of the subpopulation most likely to derive clinical benefit from everolimus should be further explored.

In addition to the presence of peritoneal metastasis and number of metastatic sites, expression of $\mathrm{pS}^{\text {Ser240/4 }}$ (IHC score $<2 v s \geqslant 2$ ), a downstream target of mTOR, at baseline was significantly associated with DCR $(8.3 \%$ vs $46.7 \%, P=0.043)$ and PFS (median, 2.7 vs 1.6 months, $P=0.001)$. This finding is consistent with previous results demonstrating positive association of pS6 expression with response to temsirolimus, another agent in the class used to treat renal cell carcinoma $(P=0.02)$ (Cho et al, 2007). Patients expressing low levels of pS6 did not experience an 
pmTOR

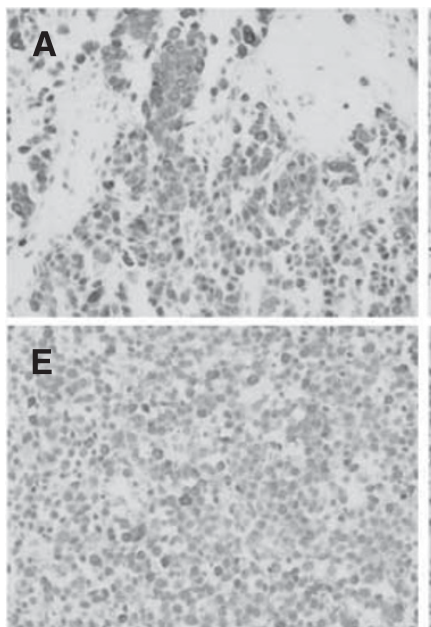

pS6K1
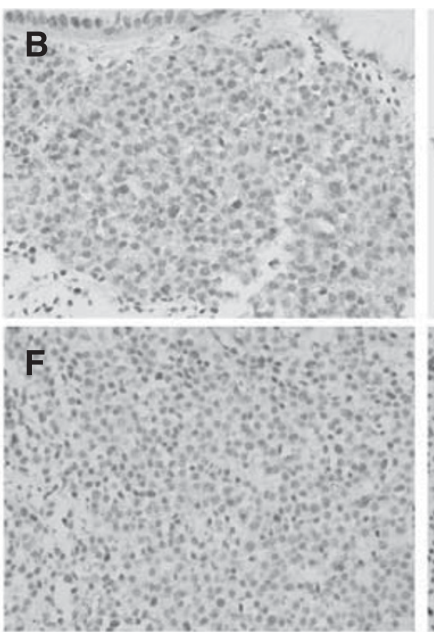

pS6 $6^{\text {Ser235/6 }}$
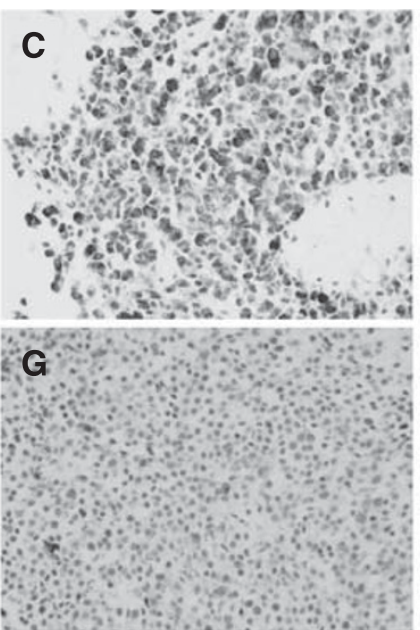

pS6 $6^{\text {Ser240/4 }}$
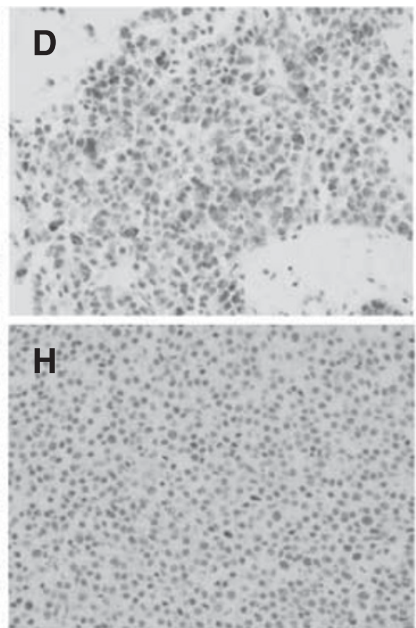

Figure 3 Biomarker expression in the tumour (pmTOR, pS6KI, pS6 $6^{\text {Ser235/6 }}$ and pS6 $6^{\text {ser240/4 }}$ ) at baseline (A, B, C and D) and after two cycles of everolimus $(\mathbf{E}, \mathbf{F}, \mathbf{G}$ and $\mathbf{H})$ in a selected patient who achieved PR.

objective tumour response. pS6 expression has also been linked to sensitivity to the rapalog, AP23573, whereby high pS6 expression is associated with clinical response among metastatic sarcoma patients, but not low expression (Iwenofu et al, 2008). We are unsure why expression of pS6K1, a downstream protein of mTOR and an attractive surrogate candidate, did not correlate with the clinical efficacy of everolimus, in contrast to $\mathrm{pS}^{\mathrm{Ser} 240 / 4}$. Immunohistochemical evaluation of pS6K1 may be misleading because of its structural similarity to p90 S6 kinase, which is not phosphorylated by mTOR (Castellvi et al, 2006) or the amplified signal change through the cascade might only have reached significant level at S6, as it is the substrate of pS6K1, which is the substrate of pmTOR. In addition to $\mathrm{pS}^{\text {Ser240/4 }}$, high expression of $\mathrm{pS}^{\text {Ser235/6 }}$ and pmTOR was significantly associated with PFS $(P=0.006$ and 0.005 , respectively), although statistical significance in multivariate analysis was not confirmed because of the small sample size. Furthermore, the extent of inhibition of mTOR signalling by everolimus was demonstrated. Specifically, the decrease in $\mathrm{pS}^{\mathrm{Ser} 240 / 4}$ and/or $\mathrm{pS}^{\mathrm{Ser} 235 / 5}$ expression after treatment with everolimus was significantly associated with prolonged PFS. On the other hand, inhibition of this pathway by everolimus may suppress the negative feedback effect of pS6K1 on an upstream adaptor protein, leading to increased phosphorylation of mTOR, as demonstrated by association of increased pmTOR level with prolonged PFS. We focused on evaluation of downstream substrates of mTOR, which are more likely to reflect the degree of mTOR activation, compared with upstream markers, including the phosphatase and tensin homologue, PI3K and pAkt, which also activate multiple downstream pathways other than mTOR. Nevertheless, our findings do not exclude the possibility that these proteins are potential predictive biomarkers of everolimus. Our findings on potential biomarkers require validation through larger retrospective and prospective trials, as we used a post-hoc definition of the criteria for predictive markers of PFS with a small number of samples and smaller number of objective tumour responses. However, these experiments were performed in a subset of the prospective cohort of the clinical trial. Consistently, tumours in which the mTOR pathway was constitutively active and/or signalling inhibited by everolimus were clinically susceptible to the drug, providing proof-of-principle.

Toxicity of everolimus was generally mild, with mostly grade 1 or 2 asthenia recorded as the leading form of toxicity (observed in $96.3 \%$ of the patients). The toxicity profile appears consistent with those reported in a large phase III placebo-controlled trial of advanced renal cell carcinoma and the Japanese phase II study
Table 3 Selected drug-related adverse events

\begin{tabular}{|c|c|c|c|}
\hline & $\begin{array}{c}\text { Grades I -2, } \\
\quad N(\%)\end{array}$ & $\begin{aligned} N & =54 \\
\text { Grades } & >2, N(\%)\end{aligned}$ & $\begin{array}{l}\text { Total, } \\
\text { N (\%) }\end{array}$ \\
\hline \multicolumn{4}{|l|}{ Haematologic } \\
\hline Leukopenia & $16(29.6)$ & $0(0.0)$ & $16(29.6)$ \\
\hline Neutropenia & $22(40.7)$ & I (1.9) & $23(42.6)$ \\
\hline Anaemia & $46(85.2)$ & $5(9.3)$ & $51(94.4)$ \\
\hline Thrombocytopenia & $42(77.8)$ & $5(9.3)$ & $47(87.0)$ \\
\hline \multicolumn{4}{|l|}{ Non-haematologic } \\
\hline Hypercholesterolaemia & $24(44.4)$ & $0(0.0)$ & $24(44.4)$ \\
\hline Triacy|glyceridemia & $13(24.1)$ & $0(0.0)$ & $13(24.1)$ \\
\hline Hyperglycaemia & $36(66.7)$ & II (20.4) & $47(87.0)$ \\
\hline Bilirubin & II (20.4) & $3(5.6)$ & $14(25.9)$ \\
\hline ALP & $15(27.8)$ & $3(5.6)$ & $18(33.3)$ \\
\hline AST & $29(53.7)$ & $3(5.6)$ & $32(59.3)$ \\
\hline ALT & $18(33.3)$ & $2(3.7)$ & $20(37.0)$ \\
\hline$\gamma$-glutamyl transpeptidase & $7(13.0)$ & $10(18.5)$ & $17(31.5)$ \\
\hline Hypophosphatemia & $5(9.3)$ & $9(16.7)$ & $14(25.9)$ \\
\hline Hyponatremia & $15(27.8)$ & $9(16.7)$ & $24(44.4)$ \\
\hline Asthenia & $51(94.4)$ & I $(1.9)$ & $52(96.3)$ \\
\hline Myalgia & $20(37.0)$ & $0(0.0)$ & $20(37.0)$ \\
\hline Diarrhoea & $19(35.2)$ & $0(0.0)$ & $19(35.2)$ \\
\hline Constipation & $15(27.8)$ & $0(0.0)$ & $15(27.8)$ \\
\hline Anorexia & $43(79.6)$ & $0(0.0)$ & $43(79.6)$ \\
\hline Nausea & $21(38.9)$ & $0(0.0)$ & $21(38.9)$ \\
\hline Vomiting & II (20.4) & $0(0.0)$ & II (20.4) \\
\hline Abdominal pain & $27(50.0)$ & । (1.9) & $28(51.9)$ \\
\hline Stomatitis & $41(75.9)$ & $0(0.0)$ & $4 \mid(75.9)$ \\
\hline Skin rash & $35(64.8)$ & $0(0.0)$ & $35(64.8)$ \\
\hline HFSR & $13(24.1)$ & $0(0.0)$ & $13(24.1)$ \\
\hline Haemorrhage & $17(31.5)$ & I (1.9) & $18(33.3)$ \\
\hline Pneumonitis $^{a}$ & $5(9.3)$ & $3(5.6)$ & $8(\mid 4.8)$ \\
\hline
\end{tabular}

Abbreviations: $\quad A L P=$ alkaline $\quad$ phosphatase; $\quad A L T=$ alanine aminotransferase; $\mathrm{AST}=$ aspartate aminotransferase; HFSR $=$ hand-foot skin reaction. ${ }^{a}$ Includes interstitial lung disease, lung infiltration, pneumonitis, pulmonary alveolar haemorrhage and other pulmonary toxicities.

(Motzer et al, 2008; Doi et al, 2010). However, the frequency of grade 3 or 4 hyperglycaemia was slightly higher in the present study, which may be partly attributed to the higher proportion of diabetic patients (22.2\%). As described in the study with rapamycin and Akt inhibitor, GSK690693, inhibition of the mTOR pathway may increase insulin resistance and possibly reduce $\beta$-cell 
function, necessitating vigilant glucose monitoring and active intervention to control hyperglycaemia (El-Salem et al, 2007; Crouthamel et al, 2009). Despite a generally favourable safety profile, we experienced two treatment-related mortality cases, one because of diffuse-alveolar haemorrhage and the other of cardiopulmonary dysfunction of unknown cause. In the latter case, the patient died only 8 days after the start of everolimus therapy. Although the direct cause-and-effect relationship is not clear at present, close monitoring of patients is evidently required.

In summary, everolimus monotherapy in unselected patients with AGC does not yield satisfactory therapeutic results. Further investigation is warranted in a subpopulation with tumours in which mTOR signalling is constitutively activated, characterised by high expression of $\mathrm{pS}^{\mathrm{Ser} 240 / 4}$. Our results cast a shadow over the ongoing phase III trial of everolimus in unselected AGC patients as salvage therapy. Even in cases of success over placebo, everolimus would have to surpass the effects of conventional chemotherapy regimens, such as docetaxel or irinotecan, to become standard salvage treatment, because of its high cost and relatively-low activity in unselected AGC patients. However, validation of $\mathrm{pS}^{\mathrm{Ser} 240 / 4}$ as a potential biomarker and further studies on positive predictive biomarkers for everolimus should uncover the target population susceptible to the drug and establish its role in AGC therapy, considering its long-lasting benefits in a limited number of patients.

\section{ACKNOWLEDGEMENTS}

This study was supported, in part, by Novartis.

\section{Conflict of interest}

$\mathrm{Y}-\mathrm{K}$ Kang is a consultant for Novartis, and received honoraria and research fund from Novartis.

Supplementary Information accompanies the paper on British Journal of Cancer website (http://www.nature.com/bjc)

\section{REFERENCES}

Bjornsti MA, Houghton PJ (2004) The TOR pathway: a target for cancer therapy. Nat Rev Cancer 4(5): 335-348

Castellvi J, Garcia A, Rojo F, Ruiz-Marcellan C, Gil A, Baselga J, Ramon y Cajal S (2006) Phosphorylated 4E binding protein 1: a hallmark of cell signaling that correlates with survival in ovarian cancer. Cancer 107(8): $1801-1811$

Cho D, Signoretti S, Dabora S, Regan M, Seeley A, Mariotti M, Youmans A, Polivy A, Mandato L, McDermott D, Stanbridge E, Atkins M (2007) Potential histologic and molecular predictors of response to temsirolimus in patients with advanced renal cell carcinoma. Clin Genitourin Cancer 5(6): $379-385$

Ciuffreda L, Di Sanza C, Incani UC, Milella M (2010) The mTOR pathway: a new target in cancer therapy. Curr Cancer Drug Targets 10(5): 484-495

Crouthamel MC, Kahana JA, Korenchuk S, Zhang SY, Sundaresan G, Eberwein DJ, Brown KK, Kumar R (2009) Mechanism and management of AKT inhibitor-induced hyperglycemia. Clin Cancer Res 15(1): 217-225

Doi T, Muro K, Boku N, Yamada Y, Nishina T, Takiuchi H, Komatsu Y, Hamamoto Y, Ohno N, Fujita Y, Robson M, Ohtsu A (2010) Multicenter phase II study of everolimus in patients with previously treated metastatic gastric cancer. J Clin Oncol 28(11): 1904-1910

Dufner A, Andjelkovic M, Burgering BM, Hemmings BA, Thomas G (1999) Protein kinase B localization and activation differentially affect S6 kinase 1 activity and eukaryotic translation initiation factor 4E-binding protein 1 phosphorylation. Mol Cell Biol 19(6): 4525-4534

El-Salem M, Raghunath PN, Marzec M, Wlodarski P, Tsai D, Hsi E, Wasik MA (2007) Constitutive activation of mTOR signaling pathway in posttransplant lymphoproliferative disorders. Lab Invest 87(1): 29-39

Frattini M, Signoroni S, Pilotti S, Bertario L, Benvenuti S, Zanon C, Bardelli A, Pierotti MA (2005) Phosphatase protein homologue to tensin

expression and phosphatidylinositol-3 phosphate kinase mutations in colorectal cancer. Cancer Res 65(23): 11227

Iwenofu OH, Lackman RD, Staddon AP, Goodwin DG, Haupt HM, Brooks JS (2008) Phospho-S6 ribosomal protein: a potential new predictive sarcoma marker for targeted mTOR therapy. Mod Pathol 21(3): $231-237$

Kamangar F, Dores GM, Anderson WF (2006) Patterns of cancer incidence, mortality, and prevalence across five continents: defining priorities to reduce cancer disparities in different geographic regions of the world. J Clin Oncol 24(14): 2137-2150

Kang YK, Yoon DH, Ryoo BY, Ryu MH (2010) Recent advances in chemotherapy for advanced gastric cancer. Asia-Pacific J Oncol Hematol 2(1): $67-74$

Lee JL, Ryu MH, Chang HM, Kim TW, Yook JH, Oh ST, Kim BS, Kim M, Chun YJ, Lee JS, Kang YK (2008) A phase II study of docetaxel as salvage chemotherapy in advanced gastric cancer after failure of fluoropyrimidine and platinum combination chemotherapy. Cancer Chemother Pharmacol 61(4): $631-637$

Motzer RJ, Escudier B, Oudard S, Hutson TE, Porta C, Bracarda S, Grünwald V, Thompson JA, Figlin RA, Hollaender N, Urbanowitz G, Berg WJ, Kay A, Lebwohl D, Ravaud A (2008) Efficacy of everolimus in advanced renal cell carcinoma: a double-blind, randomised, placebocontrolled phase III trial. The Lancet 372(9637): 449-456

Parkin DM, Bray F, Ferlay J, Pisani P (2005) Global cancer statistics, 2002. CA Cancer J Clin 55(2): 74-108

Velho S, Oliveira C, Ferreira A, Ferreira AC, Suriano G, Schwartz Jr S, Duval A, Carneiro F, Machado JC, Hamelin R, Seruca R (2005) The prevalence of PIK3CA mutations in gastric and colon cancer. Eur J Cancer 41(11): $1649-1654$

This work is published under the standard license to publish agreement. After 12 months the work will become freely available and the license terms will switch to a Creative Commons Attribution-NonCommercial-Share Alike 3.0 Unported License. 